histology slides are used throughout the book. The diagnostics section approaches the more common conditions seen in the dental surgery and hospital, clearly covering signs, symptoms and diagnostic tests, again aided by clear, colour clinical photographs.

As with many American text books some terminology differs from standard UK texts. Furthermore, owing to the American sources used throughout the book, care needs to be taken with the tables regarding drug regimes, and guidance should still be sought from relevant local guidelines.

This book proves to be a valuable source for undergraduates approaching clinical work and those wishing to consolidate their knowledge post-graduation. The information is clear, intelligible and facilitated by good clinical pictures with helpful tables and alert boxes highlighting the key points throughout, making this title a pleasure to use.

J. Good

\section{ORAL IMPLANTOLOGY SURGICAL PROCEDURES CHECKLIST}

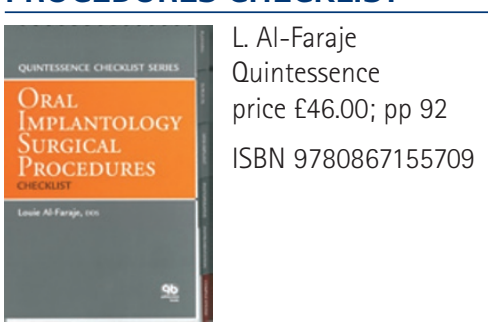

This A5 size text is presented in ringbinder format, has a card spine allowing it to stand upright, and is printed on pages that can be wiped clean. It is designed to be used as a checklist. The author states he has experience in the aviation industry where safety checklists are common and has translated this to implant dentistry.

The book is neatly laid out in six tabulated chapters making it easy to navigate. The chapters outline all stages of surgical implantology from the planning phase to postoperative management. There are also handy chapters on instrumentation, management of complications and mini implant placement.

The text does not read like a normal book. Instead, it is laid out solely in bullet points with clear step-by-step instructions for each component of implant placement/management. The idea is to work through the checklist with no stage left out, whilst also functioning as an aide-memoire.

Diagrams are limited but those which are present are simple to understand and are succinct with the text. Unfortunately, the steps proposed by the author are not referenced with regard to the current evidence-base and seem largely to be down to personal opinion. It must also be remembered that the book is written for an American audience so some of the drug doses, instruments and techniques used may need to be translated.

I found this book easy to use in practice but it was also useful for the whole dental team from setting up equipment, performing patient checks and providing postoperative advice.

For confident implantologists looking to broaden their knowledge, this book is not for you. Nor is this suitable for absolute beginners in the field of implantology. I would, however, recommend this checklist for dentists who have some experience of implantology but are looking to build their confidence with surgical procedures.

N. Patel

\section{MASTER DENTISTRY. VOLUME 1: ORAL AND MAXILLOFACIAL SURGERY, RADIOLOGY, PATHOLOGY AND ORAL MEDICINE, 3RD EDITION}

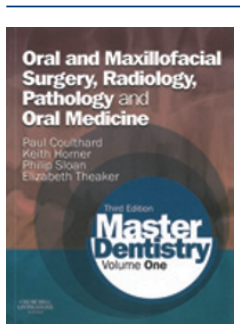

P. Coulthard, K. Horner P. Sloan, E. Theaker Churchill Livingstone price £29.99; pp 272 ISBN 9780702046001

Having owned the first and second editions of this highly acclaimed and popular volume of books, the third edition very much continues from the successes of the previous two volumes, whilst continuing to be refined to satisfy the needs of its target readers who are notably undergraduate students, general dental practitioners and postgraduate students preparing for the MFDS/MJDF examinations, as well as international students sitting the ORE exam.

This book encompasses four major disciplines of dentistry in 16 easy to read, well laid out chapters. Each chapter begins with an 'overview' that explains what the chapter will cover. This is then followed by 'learning objectives' that act as a checklist for the topics covered. The refinements of the third edition are clearly demonstrated in its illustration of the text; for starters the font is larger and easier to read, moreover, the clinical photographs and illustrated diagrams are larger and clearer to view. There is a positive improvement in the paragraph layout with concise bullet points to list important information within the context, giving the impression of written notes, thus making information more easily retrieved.

Like the previous editions each chapter finishes off with a self-assessment section in the form of MCQs, extended matching questions, case reports and oral exam questions to complement the setup of most undergraduate and postgraduate examinations. This section will be valuable to students as it offers them feedback on their performance in that particular subject or chapter.

In my opinion the oral medicine and pathology chapters excel in covering a topic most of us found challenging at undergraduate level. Each chapter leads the reader through the clinical signs and symptoms, pathology, radiological features and management, which are backed up with excellently presented coloured pictures and histological slides, well-defined radiographs and drawn diagrams.

Whilst it would be fair to say that the third edition of Master dentistry, volume 1 hasn't been radically overhauled, it still maintains all the components that make it an excellent book to own. The broad coverage of topics within this edition will appeal to many students; however, this book should be viewed as a complement to existing textbooks and should not be seen as a replacement alternative. With that in mind, it will maintain itself as an invaluable study aid for many students and will find its place in many undergraduate and postgraduate students' bookshelves.

A. Al Hourani 